\title{
Concepciones de la cooperación social: Weber y Mises
}

\section{Conceptions of Social Cooperation: Weber and Mises}

https://doi.org/10.15332/iust.v0i15.2087

\section{Fernando Salazar Silva}

Docente Dpto. Economía Universidad Nacional de Colombia sede-Medellin; economista, máster en Estudios Políticos y doctorado en Economía.

Correo electrónico: fsalazar75@hotmail.com

\author{
Santiago José Sánchez Serrano \\ Economista por la Universidad Nacional de Colombia sede-Medellin. \\ Correo electrónico:sjsanchezs@unal.edu.co
}

\section{Resumen}

En el presente artículo se abordan dos autores Max Weber y Ludwig Von Mises, quienes asumen el mercado libre como un mecanismo de coordinación de las distintas valoraciones individuales. Si bien se ha insistido en una profunda separación entre ellos, a partir de sus concepciones de la acción humana, se puede rastrear, en la forma como los autores estudian los fenómenos sociales, la existencia de una conciencia para cooperar por parte de los individuos.

Palabras clave: Cooperación social, valor, mercado, guerra, división del trabajo, cálculo económico.

\section{Abstract}

In this article are discussed two authors Max Weber and Ludwig von Mises, who adopt the free market as a mechanism of coordination in individual valuations. Even if it has been insisted on a deep separation between them, from their conceptions of the human action, can be traced, in the way how the authors study social phenomenas, the existence of a conscience to cooperate on the part of individuals.

Keywords: Social cooperation, value, market, war, division of labour, economic calculation.

\section{Résumé}

Dans le présent article sont abordés deux auteurs Max Weber et Ludwig Von Mises, qui assument le marché libre comme un mécanisme de coordination des différentes évaluations individuelles. Bien que l'on ait insisté sur une séparation profonde entre eux, basée sur leurs conceptions de l'action humaine, on peut retracer, dans la façon dont les auteurs étudient les phénomènes sociaux, l'existence d'une conscience à coopérer de la part des individus.

Mots-clés: Coopération sociale, valeur, marché, guerre, division du travail, calcul économique.

JEL Classification: A12, A13, A31, B31, B41 



\title{
Concepciones de la cooperación social: Weber y Mises
}

\author{
Fernando Salazar Silva \\ Santiago José Sánchez Serrano
}

\section{INTRODUCCIÓN}

La influencia del pensamiento científico y la concepción de mundo están presentes en las teorías económicas. El pensamiento involucra una idea de la realidad y por supuesto su relación con ella. La capacidad interpretativa de abordar los problemas sociales en autores como Weber y Mises se harían incomprensibles en ausencia a la filosofía de la ciencia. Qué hacen estos pensadores, sino construir teorías con el objeto de comprender la realidad en permanente cambio y evolución, se entiende de esta manera que la ciencia tiene su origen en horizontes filosóficos y metafísicos.

Los equívocos o aciertos sobre la actividad creadora de estos intelectuales, muestra el camino de ese pensamiento en movimiento en relación con la superación de la compatibilidad e incompatibilidad entre azar y razón, y esto es importante para un orden social en el que impera el cambio indirecto. La indagación sin límites de la acción humana por la creación de riqueza revela la causalidad física. En este sentido, el gran esfuerzo teórico deja por fuera los hechos experimentales y enfatiza la realidad de los hechos, es reconocer el problema económico razonadamente en torno a la revolución metodológica sobre la acción humana.

Esta transformación de concepción es la muestra de la implicancia de las ciencias en la naturaleza del hombre. Así, se dan a la tarea de indagar y no probar, sobre un orden social que está en constante movimiento. Cabe resaltar entonces que, cada pensador procede a poner en marcha su ejercicio creador; logrando manifestar el sustrato de la acción humana, es decir, se invirtió la cuestión metodológica, el ambiente de un orden estable se desvanece. La obra de estos autores proviene de una concepción nueva del orden social en cuyo seno se hallan las acciones humanas de carácter racional en el contexto de la incertidumbre.

El pensamiento de Weber y Mises se ha asumido como el saber en cada uno de sus momentos, el cual ha permitido acercarnos a la ley del desenvolvimiento de la historia y la comprensión del método de trabajo que subyace en ella. Esto genera un sugestivo desafío, y este es el problema, el cual tiene una salida humana, que es el 
diálogo. El mundo moderno tiene a su haber los debates en torno a los fundamentos de la ciencia que se gestó en el Renacimiento (el realismo con plena certeza y el conocimiento humano como un simple instrumento de predicción) y entra en conjunción con la comprensión de conocimiento propia, las conjeturas o no certeza de la realidad.

El hecho de vincular el 'yo' y el 'nosotros', que ha estado al margen de la historiografía económica, invita a adentrarse en los aportes teóricos del pensamiento económico en torno a la cooperación social en autores como Karl Emil Maximilian Weber (1864-1920) y Ludwig Heinrich Edler von Mises (1881-1973), pensadores que enfrentaron el problema sobre la consecución de fines particulares como consecuencia no deseada. Si el punto de partida es comprender el mercado libre como un mecanismo de coordinación de las distintas valoraciones individuales, entonces puede encontrarse puntos de convergencia entre las distintas concepciones de los autores alrededor del tema.

Finalmente, recordar que la cercanía intelectual de ambos autores gira en torno a la idea de que las acciones humanas son el punto de partida para argumentar de manera racional los medios para el logro de un objetivo. El carácter racional radica en el utilitarismo de principios que subyace en la elección de los medios para la cooperación.

\section{CONCEPCIONES SOBRE COOPERACIÓN SOCIAL}

\section{Weber: Relación asociativa y cálculo económico}

\section{Individualismo metodológico y acción social}

El enfoque metodológico de Weber se concentra en el individuo como principio y sus acciones en la mirada social y cultural. Si bien para el autor, individuo es quien subjetivamente ejerce acción, la expresión de las ideas son las motivaciones para las actuaciones de los individuos. En este sentido, acción e ideales construyen tipos $^{l}$ que explican, en términos teóricos, lo individual y sus conexiones con las particularidades de la individualidad (Weber, 1922/2014, p. 132). Se hace manifiesta la forma como la acción social expresa la relación subjetiva entre los individuos que interactúan dentro de colectividades:

Para otros fines de conocimiento (por ejemplo, jurídicos) o para finalidades prácticas puede ser conveniente $\mathrm{y}$ hasta sencillamente inevitable tratar determinadas formaciones sociales ('Estado', 'cooperativas', 'sociedad

Los tipos ideales son recursos metodológicos en Weber que corresponden a construcciones teóricas en el mundo de las ideas como medio para la investigación epistemológica. Por tanto, no se relacionan con lo singular o plural de la realidad empírica, precisamente por su carácter ideal. Los tipos categorizan la intencionalidad subjetiva de los actores sociales mediante el sentido y contenido de sus actos. 
anónima', 'fundación') como si fueran individuos (por ejemplo, como sujetos de derechos y deberes, o de determinadas acciones de alcance jurídico). Para la interpretación comprensiva de la sociología, por el contrario, esas formaciones no son otra cosa que desarrollos y entrelazamientos de acciones específicas de personas individuales, ya que tan sólo éstas pueden ser sujetos de una acción orientada por su sentido (sic) (Weber, 1922/2014, p. 139).

Los individuos se entienden como agentes subjetivos en el transcurso de una acción reconocible; esto, desde luego, imposibilita la masificación del colectivo, que constituye acciones individuales indistintas. Es cierto que Weber procura develar las ficciones del colectivo como única manera de dar sentido y significado al individuo. Es por eso que se decanta por la "acción social" antes que por la "sociedad". Para ello rescata el trasfondo de relaciones asociativas dentro de las colectividades, en las que yacen acciones interdependientes.

En este sentido, la compleja relación entre las acciones humanas y el contexto cultural puede ser explicada mediante modelos del comportamiento intencional de los individuos. Weber denominó a estos, los "tipos ideales", que obedecen a una dinámica histórica de factores accidentales e irracionales. Cabe aclarar que el tipo ideal en la obra de Weber es un recurso metodológico de su modelo teórico, por tanto, los constructos teóricos que subyacen en aquel, no existen en la realidad definible, sino en el mundo de las ideas; no obstante, proveen claves interpretativas objetivas para aproximarse a los constructos de la realidad social. El enfoque de los conceptos típicos da cuenta de los resultados de los ideales que forman las acciones sociales:

No conocemos científicamente ideales comprobables. Sin duda, eso hace nuestros esfuerzos más arduos que los del pasado, ya que esperamos crear nuestros ideales desde dentro de nuestro seno en plena época de la cultura subjetivista; pero no debemos y no podemos prometer un paraíso de engaño y un camino fácil para esto, ni en el pensamiento ni en la acción. Este es el estigma de nuestra dignidad humana, que la paz de nuestras almas no puede ser tan grande como la paz de quien sueña con tal paraíso" (trad.) (Weber, 1909, citado por Roth, p. xxxiii).

Cierto es que la práctica social gira alrededor de ideales de carácter abstracto y utópico, que impregnan de sentido lo individual y son el resultado de las acciones humanas. La herramienta de los tipos ideales investiga teóricamente las conexiones y asociaciones de las manifestaciones de la acción ${ }^{2}$ humana racional con arreglo a fines. Aunque el método de Weber podría ser lógico deductivo, vale destacar que sus esfuerzos teóricos redundan en la acción social ${ }^{3}$ como camino para entender los

2 Para Weber (1922/2014, p. 139) la "acción" se entiende como la "orientación significativamente comprensible de la propia conducta, solo existe para nosotros como conducta de una o varias personas individuales" (sic).

3 En Weber (1922/2014) el concepto de acción social es una guía para la creación de expectativas sociales acerca de las acciones ajenas, las cuales entrañan cálculos de las acciones económicas 
fenómenos de las ciencias sociales. En efecto, la forma de comprensión del autor parte de su preocupación epistemológica del individuo, su acción y sus ideales, ello sin desconocer la importancia de lo sistemático, societal y lo material.

En estas líneas argumentativas, un elemento clave en la introducción a la comprensión del mapa conceptual weberiano es la concepción de historia, en tanto contexto para la cooperación social. El sociólogo alemán concibe la historia como la evolución social de los medios y fines económicos: Los procesos históricos como el resultado de las acciones sociales (Weber, 1923/2001, pp. 3-17). Ciertamente esta postura teórica pareciese que se acerca al historicismo por cuanto las acciones sociales obedecen a un contexto histórico particular, lo cual conduce a un análisis de los motivos subjetivos de los individuos para actuar.

El interés de Weber en la acción social, empero, no radica en el contenido o predicción de los medios y fines de los actores sociales, sino en la secuencia lógica de las acciones sociales que acompañan los procesos históricos, a saber, la explicación causal de su desarrollo y sus efectos (Weber, 1922/2014, p. 129). En consecuencia, la visión histórica de Weber insiste en considerar el futuro como historia, abierto a la voluntad humana y la resolución: La acción individual en cuanto tal y sus ideales como constructoras de la historia (Roth \& Schluchter, 1979, p. 201). Esto distancia al autor de la ley de la historia a modo de método de explicación de la evolución de los procesos históricos ${ }^{4}$.

La ilustración de los resultados de la teoría sociológica y económica weberiana se reflejan en que "[...] toda la historia económica es la historia del racionalismo triunfante, basado en el cálculo" (Weber, 1923/2001, p. 16). En los hechos económicos en perspectiva histórica también influyen los fenómenos materiales e irracionales de la racionalidad formal como instrumento de la acción humana. Por tanto, el cálculo se propone como el mecanismo racional para relacionar los medios y fines de la acción humana en el devenir de la historia económica. En el trabajo titulado "Un Ensayo sobre la sociología de la religión" Weber escribe:

Una economía racional es una organización orientada por los precios monetarios, que se originan en las luchas de intereses de los hombres dentro del mercado. El cálculo no es posible sin una estimación monetaria de los precios y por lo tanto sin las luchas de mercado (1998, p. 57).

de los actores sociales: "La acción social (incluyendo tolerancia u omisión) se orienta por las acciones de otros, las cuales pueden ser pasadas, presentes o esperadas como futuras (venganza por previos ataques, réplica a ataques presentes, medidas de defensa frente a ataques futuros). Los 'otros' pueden ser individualizados y conocidos o una pluralidad de individuos indeterminados y completamente desconocidos [...]” (p. 149).

4 Antes que la mera pretensión de imitar el método de las ciencias físicas y naturales, la perspectiva metodológica de Weber (1922/73) sobre las ciencias sociales y humanas es la comprensión de los problemas de la sociedad a partir de los individuos con conciencia, voluntad, acción, ideales e intenciones. 


\section{Sobre la relación medio-fin como forma asociativa}

El hombre en acción orienta sus medios para alcanzar fines, en busca de la satisfacción de los deseos. En este proceso se crea una relación medio-fin que se entrelaza mediante la razón. Tal acción adquiere el carácter de social en la medida en que su relación medio-fin se dirige a la acción de otros (Weber, 1922/2014, p. 149). La acción social, por tanto, es racional con arreglo a fines ${ }^{5}$ y valores (p. 151), es decir, la razón es el instrumento de resolución de la acción. De ello, en el encuentro de relaciones medio-fin surge una cierta unión de fines que forma la asociación.

Actuar asociado es un actuar en comunidad en la medida en que se oriente a expectativas sobre los ordenamientos sociales establecidos de manera racional y subjetiva con relación a fines (Weber, 1922/73, p. 191). En efecto, la relación mediofin asocia los individuos en las actividades económicas:

Decimos que una actividad es económica cuando está orientada a procurar 'utilidades' (bienes y servicios) deseables o las probabilidades de disposición sobre las mismas. Toda actividad puede orientarse económicamente, aun la del artista y la del guerrero, esta última en cuanto los fines y medios económicos son de interés para la preparación y realización de la guerra. Sin embargo, en sentido estricto, 'economía' implica sólo el ejercicio pacífico de un poder de disposición que, de modo primordial, está económicamente orientado. Una de las características del poder de disposición es la referente a la propia fuerza de trabajo (sic) (Weber, 1923/2001, p. 3).

En este sentido, se genera una interdependencia de medios y fines individuales que revelan lo económico de las relaciones sociales en el contexto de la asociación. Los impulsos que en cierta manera orientan esta relación asociativa entre medio y fin son los intereses que manifiestan las acciones sociales:

Son los intereses, materiales e ideales, no las ideas, quienes dominan inmediatamente la acción de los hombres. Pero las 'imágenes del mundo' creadas por las 'ideas' han determinado, con gran frecuencia, como guardagujas, los raíles en los que la acción se ve empujada por la dinámica de los intereses (sic) (Weber, 1920/98, p. 247).

Los intereses de estos tipos son expresiones de las voluntades de los individuos que buscan realizar racional e intelectualmente conceptos típicos más allá de la acción y las ideas; los intereses condicionan la orientación de las acciones hacia otras. Weber interpreta la asociación de los individuos en el contexto de la relación medio-fin desde la perspectiva del cálculo de las acciones económicas. Justamente, las relaciones asociativas configuran las condiciones para la cooperación social

$5 \quad$ La racionalidad teleológica, según Weber (1904-5/2011 y 1922/2014), se preocupa por coordinar la estabilidad de los ordenamientos sociales y las relaciones de dominación. Las actuaciones con arreglos a fines y a valores y se orientan por estos tipos de relacionamiento social. 
(Weber, 1923/2001, pp. 3-9); el mercado libre, por ejemplo, no es más que una relación asociativa en la vida económica, que propone condiciones para la vida social:

[...] aparece ahora como tipo de todo actuar racional en comunidad la relación asociativa [...] que, en virtud del cambio, tiene su escenario en el mercado. Debe hablarse de un mercado tan pronto como concurren, aunque sólo sea de una parte, una pluralidad de interesados en el cambio y en las probabilidades de cambio. [...] el mercado representa relaciones asociativas racionales, coetáneas y sucesivas; cada una de las cuales tiene un carácter efímero ya que se extingue con la entrega de los bienes de cambio a no ser que se haya dictado - otorgado- un ordenamiento que imponga al que cambia frente a su parte contraria la garantía de evicción (de la adquisición 'legal') (sic) (Weber, 1922/2014, pp. 694-695).

De esto se deduce que la cooperación social en Weber es un tipo ideal, vale aclarar, una imagen del mundo del intercambio y del trabajo, en el que se encuentran los intereses asociativos de las acciones humanas. Aquella caracterizada por una realización racional e intelectual y por un "desencantamiento del mundo" (Weber, 1904-5/2011).

En la forma asociativa los individuos son en y para sí medios económicos con relación a los otros (Weber, 1923/2001, p. 3). De este modo, los contactos asociativos crean imágenes del intercambio que dan lugar a conceptos típicos de situaciones fácticas como el apoyo, colaboración, ayuda, empatía. Estos tipos "simples" llegan a ser tipos ideales en cuanto los medios económicos se aparecen como recíprocos a las acciones individuales. En este momento, los tipos singulares y plurales de la vida económica se tornan en supraindividuales. Es el caso de la cooperación social como tipo ideal de las acciones económicas, que, en cierta manera, se nos puede antojar de naturaleza fáctica. Sin embargo, cuando el individuo renuncia a su medio económico para aceptar otro, lo hace con el interés material e ideal de contribuir a la satisfacción de sus propias necesidades. Este interés se encuentra con el de otro con arreglo al ideal recíproco de la asociación: Un algo dentro de los resultados de las acciones económicas que está por encima del individuo, sus ideas e intereses: la cooperación social ${ }^{6}$.

En virtud de su preocupación epistemológica del individuo, la cooperación social es una idea de la realidad concreta o el contenido de la materialidad de las cosas, siendo así, es un ideal que coordina la dinámica de las acciones económicas. Implica ideal en tanto hay asociación recíproca; es decir, entretanto las acciones individuales se corresponden mutuamente con arreglo a fines y valores. Con esto presente, puede afirmarse que la asociación como idea concreta de la cooperación social se eleva desde el orden de lo real al orden de los valores. Cambian, por supuesto, las relaciones hombre-hombre y hombre-naturaleza. Ya no sería el mero cambio de cosas o medios económicos -los

6 En el intercambio, en sentido estricto, los actores de las distintas religiones se comportan como si estuvieran en la misma religión. En este fenómeno, tanto el judío como el mahometano, al igual que el cristiano no se detienen a reflexionar a la persona con quien intercambian, simplemente prestan atención a sus necesidades humanas y a la situación del otro. Al salir de estos encuentros pacíficos y libres, cada practicante vuelve a su contexto religioso con sus necesidades parcialmente satisfechas. 
cuales guardan o revisten ideas- por otros, sino el intercambio de intereses materiales e ideales, imágenes estas del mundo espiritual de la cooperación social.

\section{Sentido de la relación asociativa}

El desarrollo interno de la asociación entre individuos crea relaciones sociales que se pueden entender como la formación de una conducta plural que se orienta por la reciprocidad entre las acciones. El contenido de la relación social es la probabilidad de que cada individuo actuará socialmente en una forma con sentido indicable (Weber, 1922/2014, p. 154). Significa esto que los actores sociales en asociación crean expectativas acerca de la forma y sentido de las acciones de sus semejantes. En realidad, el actuar asociado de los individuos, que incluye la relación social, orienta con sentido la relación asociativa de medios y fines. Este actuar de hecho, sin embargo, trasciende lo fáctico en tanto se orienta a ordenamientos de la unión de fines como tipo ideal racional de la asociación (Weber, 1922/73, pp. 191-201). Justamente de aquí surge el tipo ideal de la cooperación social como relación asociativa?:

Dentro del actuar orientado según el pacto se encuentra el tipo más importante de actuar en sociedad «referido socialmente», por un lado el actuar en sociedad específico de los «órganos», por el otro el actuar en sociedad de los asociados, el cual se refiere de manera provista de sentido a aquel actuar de los órganos. En especial, dentro de la categoría perteneciente a la asociación- de las «instituciones» [...] se suelen distinguir los ordenamientos creados para la orientación de este actuar [...] de los que rigen las otras acciones de los individuos asociados (sic) (Weber, 1922/73, pp. 196-197).

A este último respecto, la cooperación social sobrepasa el carácter fáctico de la asociación. En la relación asociativa de los medios y fines económicos, por otro lado, surgen tipos en el encuentro de los intereses ideales y materiales. No obstante que el contenido de tal relación asociativa es la interacción de las expectativas mutuas de las acciones humanas, se hace necesario interpretar su sentido para rastrear la orientación de los actores sociales:

Todo actuar en sociedad es naturalmente expresión de una constelación de intereses de los participantes, dirigida a la orientación del actuar, tanto del ajeno como del propio, según sus ordenamientos específicos y ningún otro, y por lo tanto configurado de muy diversas maneras. Su contenido admite ser caracterizado de manera enteramente general y formal [...] en cuanto que los individuos creen tener un interés en poder contar con un actuar pactado a través de la asociación de parte del otro o de los otros y orientar de acuerdo con él su propio actuar (sic) (Weber, 1922/73, pp. 200-201).

7 La relación asociativa en Weber (1923/2001) está presente entre dos órdenes económicos: consuntivo y lucrativo. Toda asociación en el orden social combina entre las acciones económicas tanto la finalidad consuntiva como el acto de lucro. Por tanto, entre consumo y dinero los individuos articulan económicamente cálculos de las prestaciones utilitarias y humanas de los bienes y servicios. 
Es claro que el mapa de orientación de la acción humana en el orden social son las valoraciones de los medios económicos, las cuales se compendian en los intereses y se sintetizan en los precios. En este punto, llegamos al cálculo económico como sentido de la relación asociativa. Su contenido son los intereses materiales e ideales que surgen en las expectativas sociales de los hombres acerca de las acciones de los otros. El ideal del cálculo económico en Weber, por tanto, es una forma de racionalización de la relación medio-fin en la acción social. Es un recurso comprensivo que da sentido a la relación asociativa, es decir, orienta y direcciona el actuar asociado con atención a los precios.

El cálculo económico incorpora un mecanismo para la creación individual de probabilidades acerca de los intereses y valoraciones subjetivos en un horizonte temporal. Por otra parte, Weber plantea el problema del cálculo económico y, por tanto, su imposibilidad, como la ausencia de una determinación subjetiva de precios, lo cual conduce al problema de la imputación, a saber, la indeterminación de los precios relativos de los bienes y servicios económicos. A ver:

El cálculo natural ${ }^{8}$ para los fines de una gestión económica permanente y racional de los medios de producción tendría que encontrar 'índices de valor' para cada uno de los distintos objetos, los cuales tendrían que asumir la función de los 'precios de balance' en la contabilidad moderna. De no hacerse así, ¿cómo podrían desarrollarse y controlarse los medios de producción de una manera diversa, por una parte, para cada explotación (según su localización) y, por otra parte, de manera unitaria desde el punto de vista de la 'utilidad social', es decir, de la demanda de consumo (actual y futura)? [...] No se arregla nada con la creencia de que, una vez se enfrente uno de un modo decidido con el problema de la economía sin dinero, 'ya se encontrará' o se inventará el sistema de cálculo apropiado: el problema es fundamental de toda 'socialización plena', y no puede hablarse, en todo caso, de una 'economía planificada' racional en tanto que no sea conocido en este punto decisivo un medio para la fijación racional de un 'plan' (sic) (Weber, 1922/2014, p. 229).

Lo relativo en la economía implica la posibilidad de que los valores económicos sean objeto de intercambio. Precisamente es mediante los medios de valor objetivo, en este caso el dinero y los precios, que en el intercambio se establece el carácter relativo de los valores y fines económicos. En este escenario, el cálculo económico en Weber toma forma con las "probabilidades de mercado", es decir, con la lucha pacífica entre los seres humanos. Esto crea "probabilidades de lucha" en el mercado que interconectan las expectativas sociales de los actores económicos: "De aquí resulta la racionalidad 'formal' de la economía monetaria, en comparación con la economía 'natural' (ya sea con o sin cambio). Implica la máxima 'calculabilidad'

$8 \quad$ El cálculo natural es el reflejo de la racionalización de las acciones individuales, las cuales no emplean el dinero como elemento de calculabilidad. Este hecho, por supuesto, no posibilita la racionalidad calculatoria de la actividad económica (Weber, 1923/2001, p. 7). 
posible, el cálculo completo de todas las probabilidades de ganancia y pérdida ya realizadas o esperadas para el futuro (Weber, 1923/2001, p. 9).

Ciertamente la noción de valor y su manifestación en la valoración intersubjetiva, el precio, son sustantivos en la constitución del pensamiento de los actores económicos. En cierta manera, el individuo se acerca - o se aleja- al otro, a la naturaleza a partir del significado y sentido que le merecen su apariencia o contenido. Esto orienta la vida social del ser humano. Por lo que, construir una idea del mundo sin valor no revela la naturaleza humana. Weber insistió en que las valoraciones individuales no son el resultado de una respuesta psicológica al mundo externo, sino que son un arreglo de sus preferencias, indudablemente, ante asignación de los medios escasos.

Ahora bien, cuando el valor y la valoración propias de los individuos son determinadas por un tercero, tal interconexión de valoraciones en el cálculo económico no devienen en un resultado del actuar asociado como tipo ideal, sino en una reelaboración artificial de las acciones sociales, lo cual aparece extraño al actuar humano debido a la procedencia reconfigurada del valor. Resultando que no hay posibilidad para el cálculo económico porque los precios no representan el actuar social, sino el actuar aislado o natural de una mente razonadora; la acción, por ende se supedita a la razón, esta deja de ser medio que orienta el actuar para convertirse en principio de su misma acción y la de los demás.

\section{Mises: La cooperación social}

\section{Praxeología: De la acción humana a la cooperación social}

La metodología de investigación económica pura de Mises aborda el estudio general de la acción humana como presupuesto teórico en la comprensión de los fenómenos económicos y sociales desde un enfoque humano: la praxeología. En este sentido, la operación del sistema económico es una constelación de relaciones medio-fin que expresan la intencionalidad de los seres humanos en el propósito de cambiar sus estados de satisfacción. La acción humana que entraña este proceso se conceptualiza así:

La acción humana es una conducta consciente, movilizada voluntad transformada en actuación, que pretende alcanzar precisos fines y objetivos; es una reacción consciente del ego ante los estímulos y las circunstancias del ambiente; es una reflexiva acomodación a aquella disposición del universo que está influyendo en la vida del sujeto (sic) (Mises, 1949/2007, p. 15).

De acuerdo con este basamento filosófico y metodológico para la economía como disciplina praxeológica, la acción humana es una noción epistemológica trasversal a la obra de Mises (Rothbard, 1973/2009, pp. 31-34). Además, desde la mirada individual, es una conducta intencional que emplea medios para alcanzar fines. Su carácter es teleológico, consciente, deliberado y voluntario. Bajo este axioma fundamental, en el encuentro de las acciones humanas, en cambio, el carácter no deliberado de la relación medio-fin adquiere relevancia debido a la complejidad e incertidumbre 
del actuar humano y social. De esta manera, Mises (1949/2007) toma distancia del hombre racional económico y propone al hombre racional humano (pp. 15-35).

El método praxeológico de Mises consiste en el estudio del individuo como unidad principal de análisis, con una independencia de la intuición sensible para analizar las actuaciones humanas y luego deducir en la praxis social. Si bien Mises toma en consideración la experiencia inmediata, no es necesariamente su punto de partida para estudiar la acción humana, ya que el conocimiento de la acción no se deriva de la experiencia, sino de la razón y sus juicios a priori.

En términos epistemológicos, de acuerdo con Zanotti (2010) y Eshelman (1993), el núcleo central del pensamiento de Mises se compone por su utilitarismo, su noción de cooperación social y civilización. El primero, se caracteriza por el surgimiento de principios a partir del proceso y naturaleza de la acción humana, en concreto, por el utilitarismo de principios, de valores sociales irrenunciables, que difiere de las miradas benthamita y hedonista; la segunda, es un valor espiritual del intercambio y la división del trabajo como principios del mercado y el comercio, y la tercera, constituye un principio rector en la obra del economista austríaco, es decir, es un conjunto de valores que rige la dinámica y encuentro de las acciones humanas (pp. 117-125 y pp. 3-41, respectivamente).

En Mises el tránsito de la acción humana a la cooperación social se presenta en la continua búsqueda y descubrimiento de los medios que posibiliten la configuración de un conjunto de valores transversales al orden social. En tanto imperativo categórico, estos valores irrenunciables como propiedad, mercado, libertad, etc., que implican acción humana, conforman lo que se llama civilización. Aunque la cooperación social es otro valor más, su papel es vincular tal conjunto de valores a través de los principios de asociación como el intercambio y la división del trabajo, que hacen parte de las leyes praxeológicas de la acción humana (Kirzner, 2001, pp. 79-81).

Según lo anterior, el contexto de la praxeología se podría ubicar en el horizonte histórico. La concepción de historia en Mises es de tipo coyuntural, comprende la historia como la interpretación de la evolución económica y social de las ideas y la acción humana de acuerdo con las relaciones medio-fin. Es decir, el proceso histórico es de característica praxeológica. Desde este sentido, la historia en la perspectiva de la cooperación social es la historia de la sociedad comercial por cuanto implica el relacionamiento de medios en la esfera económica, en procura de un fin particular. En Mises, el sentido del contenido de la historia y de sus fenómenos complejos es el estudio de la acción humana en general, la praxeología:

La historia estudia la acción humana, es decir, las acciones ejecutadas por individuos y por grupos de individuos. Describe las condiciones bajo las cuales las personas vivieron y la manera en que reaccionaron a esas condiciones. Su tema son los juicios de valor ${ }^{9}$ y las finalidades que los

9 Los juicios de valor expresan las valoraciones subjetivas (o subjetivistas) sobre los medios que emplean las acciones humanas con relación a fines. 
hombres han perseguido guiados por esos juicios de valor, los medios a los cuales han recurrido para alcanzar las finalidades perseguidas y el resultado de sus acciones. La historia estudia las reacciones conscientes del hombre a las condiciones de su medio, tanto natural como social, determinado por las acciones de generaciones anteriores así como por las acciones de sus contemporáneos (Mises, 1957/2003, p. 191).

Dentro del proceso en el cual dos o más individuos realizan intercambios y valoraciones de bienes y servicios por un consentimiento y voluntad mutua, sobresale la noción principal de historia económica ${ }^{10}$. No obstante, faltaría un aspecto dinamizador de tal proceso: la acción humana. La individualidad y la irracionalidad son conceptos característicos de la historia y por demás, caracterizan la acción humana como una explicación de la conducta humana en la historia (Mises, 1949/2007, p. 15). Ahora bien, la historia de la humanidad es la historia de las ideas y de la acción humana, se plantea la totalidad de las vicisitudes de la experiencia humana (Mises, 1957/2003, p. 215):

Cada individuo nace en un medio social y natural. Un individuo no es simplemente un hombre en general que la historia puede considerar en abstracto. Un individuo es, en cualquier momento de su vida, el producto de todas las experiencias que tuvieron sus antepasados más la que él mismo ha ido acumulando. Un hombre real vive como miembro de su familia, de su raza, de su pueblo y de su época; como ciudadano de su país; como miembro de un grupo social determinado; como practicante de una cierta vocación. Está imbuido de ideas religiosas, filosóficas, metafísicas y políticas, que a veces el enriquece o modifica por medio de su pensamiento. Sus acciones son guiadas por ideologías que ha adquirido a través de su medio (Mises, 1957/2003, p. 215).

\section{Cooperación humana: convivencia y coexistencia social}

En la obra de Mises la cooperación social es el elemento central para dar sentido y justificación a la acción humana. No es posible concebir la acción del hombre en ausencia de cooperación, ya que esta es un valor de aquella. Entretanto la primera es la expresión de la relación causal medio-fin; la segunda, es una acción que en principio es intencional, pero cuando se pone en consideración del contexto social se torna no deliberada. El punto de encuentro entre la acción humana y la cooperación social, por lo tanto, es la sociedad como marco social de acción concertada, creada

10 Según Mises (1957/2003), con relación a la noción de historia económica: "la historia de la humanidad es la historia de la intensificación cada vez mayor de la división del trabajo. [...] Lo que hizo posible la cooperación entre los hombres fue el hecho de que el trabajo realizado bajo el sistema de la división de tareas es más productivo que los esfuerzos aislados de individuos autárquicos y el hecho de que la razón humana es capaz de aprehender esta verdad" (p. 254). Los conceptos claves para la historia económica, por tanto, son el desarrollo de la cooperación social voluntaria y de la división del trabajo (Mises, 1919/83, p.165). 
por la acción recíproca de individuos interdependientes, no por un arreglo social deliberado. En estas últimas líneas, la cooperación deliberada se torna en no deliberada en la asociación e interacción social en ausencia de un diseño humano de las relaciones sociales (Mises, 1949/2007, p. 173).

Aquello que permite distinguir el animal social y político del animal biológico es la cooperación social (Mises, 1927/2002, p. 24). En la competencia biológica los animales se aniquilan unos a otros por medio de la fuerza con miras a la supervivencia. En este escenario no hay un tuyo y un mío, no hay propiedad. En cambio, dentro de la competencia social los seres humanos enfrentan el problema de la escasez y la propiedad por medio de las ventajas del intercambio y la división del trabajo (Mises, 1957/2003, pp. 86-91). Esta distinción es necesaria para advertir los beneficios del valor de la cooperación social como factor civilizador de las relaciones humanas en el contexto socioeconómico, es decir, una virtud para la vida en sociedad (Mises, 1927/2002, p. 33).

La cooperación social, en Mises, se basa en valores no absolutos (Zanotti, 2010). De esto se deduce que los medios de aquella no son de carácter circunstancial o relativo en cuanto a lugar y tiempo (pp. 121-122). Este utilitarismo no circunstancial propone que no es cualquier medio el que posibilita la cooperación social, sino aquel que propicie el encuentro de las acciones humanas como valor irrenunciable, por ejemplo, la propiedad, la libertad, la democracia, entre otros tantos que componen el orden social (p. 117). Esto clarifica el tránsito ético del estado de naturaleza al estado de civilización:

Todas estas doctrinas éticas no han podido comprender que fuera de los lazos sociales y antes, temporal o lógicamente de la existencia de la sociedad, no hay nada a lo cual pueda aplicarse el término "justo". Un individuo hipotéticamente aislado debe considerar, bajo la presión de la competencia biológica como enemigos mortales a todos los demás. Su única preocupación es preservar su propia vida y salud; no tiene que preocuparse de las consecuencias de su propia supervivencia para los demás; no necesita la justicia. Sus únicas tareas son la higiene y la defensa. Pero en la cooperación social con otros individuos el individuo se ve obligado a abstenerse de la conducta que es incompatible con la vida en sociedad. Solo entonces surge la distinción entre lo que es justo y lo que es injusto, la cual se refiere invariablemente a las relaciones sociales entre las personas (Mises, 1957/2003, p. 100).

Mediante la cooperación social, entonces, los seres humanos conviven y coexisten sin un intento deliberado de las intenciones individuales en el momento del contacto. En Mises, aquella es el elemento central para dar sentido y justificación a la acción humana. No es posible concebir la acción del hombre en ausencia de cooperación, ya que esta es un valor de aquella. Entretanto la primera es la expresión de la relación causal medio-fin; la segunda, es una acción que en principio es intencional, pero cuando se pone en consideración del contexto social se torna no deliberada. 
El espíritu de la cooperación social comprende el intercambio y la división del trabajo, elementos esenciales estos del proceso social y revolucionario del orden económico (Mises, 1919/83, p. 237). La característica que recogen estos dos principios es la asociación. Esto es, la sociedad y cooperación humana en tanto corolarios se rigen por la ley de asociación, que muestra los efectos que produce el principio de la división del trabajo en la colaboración entre trabajadores eficientes e ineficientes. Este fenómeno social fundamental muestra porqué la historia humana es la gradual intensificación de la cooperación humana. La asociación que conlleva la división del trabajo constituye el incentivo para salir del estado de guerra total y desembocar en el estado de civilización; fue la comprensión de la acción humana de esta percepción de la mayor productividad del trabajo, bajo su división, la que procuró el desarrollo de la sociedad primitiva a la humana (Mises, 1949/2007, pp. 189-193). En esta perspectiva, la cooperación no deliberada es para la sociedad humana el medio para establecer los lazos entre los valores sociales que configuran la civilización.

En este orden de ideas, Mises explica desde la praxeología la acción racional del individuo y su valoración de los medios como relación causal con los fines (Mises, 1949/2007). El papel de la cooperación social en este contexto muestra el valor de la asociación voluntaria entre individuos como la permanente búsqueda de valores relativos, en resumen, el valor de la cooperación social como un principio de la sociedad de intercambio de valores a través del mercado libre. A este tenor, la acción humana de cooperar se torna en un medio que plantea la elección entre el estado de la civilización o el 'estado natural': competencia social y competencia biológica como un problema de valores.

Desde el principio de la civilización, la inmensa mayoría de los hombres ha estado de acuerdo en preferir los efectos producidos por la cooperación pacífica, al menos entre un número limitado de personas, a los efectos del aislamiento hipotético de cada individuo y la hipotética guerra de todos contra todos. Han preferido la civilización al estado natural, puesto que perseguían la mejor realización posible de ciertos fines -la preservación de la vida y la salud--, los cuales, como ellos correctamente creyeron, requieren la cooperación social. Pero es un hecho que también ha habido y hay hombres que han rechazado estos valores y, en consecuencia, que prefieren la vida solitaria a la vida dentro de la sociedad (Mises, 1957/2003, p. 85).

La civilización es un resultado lógico de la cooperación pacífica y voluntaria del trabajo humano. De ahí que la referencia a la cooperación social y sus formas sea recurrente en la obra de Mises. Además, la apreciación que se confiere a la cooperación social es sustantiva en la comprensión de la sociedad capitalista. Esta expresión implica en el autor en mención un orden social orientado al comercio, no es solo el mero hecho de poder poner en contacto los productos del trabajo, sino que la puesta en escena del flujo de bienes, requiere que se comprenda en ausencia de coacción arbitraria. En este sentido, la sociedad comercial, por supuesto, incluye presupuestos que van más allá de las visiones de la cooperación social deliberada. 


\section{El mercado libre y la civilización}

El mercado como proceso ${ }^{11}$, en Mises, es la instancia civilizadora de las relaciones humanas. Esto significa que es el encuentro libre de las valoraciones económicas de las acciones humanas mediante su vinculación, a partir de la cooperación social. Estas valoraciones de los medios económicos es lo que permite a los individuos calcular y orientar su relación medio-fin por medio de la razón. Por ende, el problema subyacente al mercado es el cálculo económico: la interacción y asociación de las valoraciones subjetivas, la determinación de precios:

Siempre estará sucediendo que nuevos hechos aparecen, los cuales las personas no han previsto, y que hacen a ellos decir después del evento que habrían actuado diferente si hubieran conocido de antemano qué iba a sobrevenir. Las personas no pueden tener en cuenta en sus actividades económicas las cosas que son desconocidas para ellos. No podemos, por tanto, culpar el método del cálculo económico del sistema capitalista, que opera sobre la base de los precios monetarios del mercado, por el hecho de que las expectativas de los sujetos económicos son ocasionalmente decepcionadas por la aparición de eventos imprevistos. En el cálculo económico se toma en cuenta la configuración futura de las condiciones de oferta y demanda sólo en la medida en que las personas prevean éstas, o se piense que pueden preverlas, en el presente. Esto es meramente las expectativas del empresario acerca del futuro que influencian la situación del mercado de hoy y contribuyen a la formación de los precios de hoy: Esto aplica particularmente a los precios de los medios de producción y de los bienes de consumo que no perecen rápidamente (trad.) (Mises, 1938/2000, p. 31).

El punto de discusión del problema del cálculo económico son los límites a la influencia y ejercicio del poder político en la vida socioeconómica. Es en este escenario en el cual adquiere relevancia la posibilidad o imposibilidad del mercado libre. Mises (1922/62) señala una paradoja en la planificación central del cálculo económico, que la intención latente en el control de precios relativos es generar orden, pero en realidad es la antesala al caos ${ }^{12}$. La separación de los precios del proceso de mercado impide el mecanismo de la creación de señales que indican la escasez de los bienes y servicios en el mercado.

Este análisis llama la atención sobre el enfoque de la cooperación social en el mercado libre. En otros términos, sobre la compatibilidad o no de la planificación

11 La noción de proceso en Mises significa el discontinuo descubrimiento de la relación medio-fin que alcance mayores estados de satisfacción en la tendencia al equilibrio económico. De ahí que los desequilibrios son los encuentros de fuerzas humanas opuestas que tienden al equilibrio de mercado, sin alcanzarlo.

12 Por su parte, Hayek (1931/67) considera esta línea argumentativa y la ubica en el contexto del proceso espontáneo. Reconoce que el carácter espontáneo de los precios genera orden; y la regulación de precios produce caos. Esta distinción se presenta debido a las dificultades en la creación de señales que expresan la valoración económica libre de agentes económicos sobre los bienes y servicios, esto es, la imposibilidad del cálculo económico. 
central con el mercado libre, el autor se decanta por la cooperación social como un valor en sí mismo relacionado con el mercado libre en el contexto del orden económico capitalista:

[...] En la economía capitalista es posible hacer cálculos sobre la base de nuestro conocimiento del presente. Puede ser que se cometerán ocasionalmente errores porque los eventos imprevistos interfieren con nuestros planes y expectativas. En el estado socialista, sin embargo, ni siquiera sería posible calcular sobre la base de nuestro conocimiento actual. Aquellos que piensan que sería posible aplicar las ecuaciones de economía matemática para realizar los cálculos no ven que incluidas entre los artículos de los cuales están compuestas estas ecuaciones están las escalas de preferencia desconocidas que pertenecen a una situación que es irreal y nunca se puede realizar en la práctica. La circunstancia que aquellos desconocen frustra todos los intentos de utilizar las ecuaciones para los propósitos del cálculo económico (trad.) (Mises, 1938/2000, p. 32).

La apuesta teórica de Mises es, entonces, la vinculación entre la noción de cooperación social y el mercado libre mediante el cálculo económico. Esto obedece a su comprensión del comercio como factor civilizador de la sociedad humana, sería una especie de principio sociológico. En oposición, el elogio poético enaltece la guerra como forma de vida que ensalza lo valeroso de la condición humana, lo cual deviene en la paz como una utopía, un ideal inalcanzable, incluso, en una cuestión de debilidad. De aquí no es extraño que se entienda la competencia, por ejemplo, como metáfora o analogía de la guerra. La paz, desde esta perspectiva, dista de ser constitutivo del marco institucional y social. Sin embargo, para Mises, en el acontecer de la dinámica de las acciones bélicas se ignora los obstáculos para la configuración y consolidación de la cooperación social, y la miseria humana que de ello resulta. Contradecir esto, según el autor, es ignorar las leyes intrínsecas o praxeológicas de los lazos de cooperación social (Zanotti, 2010, p. 121).

En este sentido, subyace en la obra del autor una misión que trasciende el trabajo teórico y académico: la salvación secular de la civilización como una institución definitoria de valores irrenunciables de la sociedad humana, que está en pos de un orden social liberal, democrático ${ }^{13}$, pacífico y de libre mercado (Zanotti, 2010, p. 112). Ciertamente la extinción de la cooperación social en tanto espíritu de la operación del sistema económico supone la desaparición de las condiciones inmateriales que sustentan la sociedad humana (Mises, 1919/83, p. 238). En vista de esto, Mises deja la siguiente elección ante la crisis de la civilización:

[...] El estudio de estas leyes praxeológicas constituye el objeto propio de nuestra ciencia y de su rama hasta el momento mejor desarrollada, la

13 La noción de democracia en Mises consiste en un valor esencial, entre otros tantos, del orden social, que se configura subjetivamente mediante la asociación libre entre individuos en ausencia de acción planificada. 
economía. El saber acumulado por la ciencia económica forma parte fundamental de la civilización: es el basamento sobre el que se han edificado el moderno industrialismo y todos los triunfos morales, intelectuales, técnicos y terapéuticos alcanzados por el hombre a lo largo de las últimas centurias. El género humano decidirá si quiere hacer uso adecuado del inapreciable tesoro de conocimientos que este acervo supone o si, por el contrario, prefiere no utilizarlo. Si los hombres deciden prescindir de tan espléndidos hallazgos y menospreciar sus enseñanzas, no por ello ciertamente desvirtuarán la ciencia económica; se limitarán a destruir la sociedad y el género humano (Mises, 1949/2007, p. 1046).

\section{CONCLUSIÓN}

Pareciera que hubiera un distanciamiento irreconciliable entre Weber y Mises en torno a la economía política, pero podría no ser así. Su interés mutuo por el cálculo económico; la propiedad privada; el mercado libre; la cooperación, entre otros, hacen pensar en la influencia de Weber sobre Mises en relación con el esfuerzo metodológico empleado en la economía y en la praxeología. Aunque se desee distanciar a los autores por insistir en la presencia de caracteres de la filosofía utilitarista en Mises, es relevante llamar la atención que no es un utilitarismo de conveniencia, su utilitarismo es de principios.

Dejando de lado esto, es cierto que la cooperación social en ambos autores fue de profundísima importancia para comprender los obstáculos que la ilusión totalitaria produce a la creación de riqueza y al proceso civilizatorio.

Las reflexiones de ambos autores sobre la cooperación social remiten a uno de los valores que configura el mercado libre como conjunto de valores. Aquella es un valor en sí misma; por lo que no es posible consolidar el encuentro no deliberado entre los individuos en ausencia de ella. En este sentido, la acción humana que entraña cooperar en el escenario socioeconómico, no es más que un medio, entre otros tantos, para propiciar un proceso civilizatorio. Si la cooperación social pudiera enseñar algo sobre la historia de la sociedad humana, esto sería que aquella es en sí misma compatible con el mercado libre sí y solo si está presente la propiedad privada.

La contingencia de la realidad social enseña que la cooperación es un mundo de incertidumbre. De esto se deriva la razón por la cual el individuo requiere de un lapso de tiempo para construir expectativas acerca de las acciones de otros, por su incapacidad para "monitorear" de manera permanente el comportamiento de otros; por su incapacidad de tener completo conocimiento acerca de las motivaciones de otros, en concreto, por la dispersión del conocimiento y la dificultad del horizonte temporal y de la elección entre las acciones.

En apoyo de lo anterior, pensadores Weber y Mises anticiparon aspectos básicos para el posterior debate sobre la relación de oposición entre lo individual y lo social 
como factor principal de la sociedad de intercambio. Las intenciones de fondo muestran la asociación e interacción como formas de cohesión social bajo la división del trabajo y el intercambio en presencia de precios e incentivos.

En Weber, se manifiesta la compatibilidad entre asociación, acción social y mercado con arreglo a fines y valores, como el presupuesto esencial para el actuar asociado, configurando su forma de cooperación social. Es interesante advertir que en el núcleo central del autor la cooperación social es un tipo ideal que transita del orden de las cosas al orden de los valores. En este sentido, la asociación material e ideal del trabajo dinamiza la lucha de intereses individuales en una economía con "contabilidad monetaria".

A tenor de Mises, la división del trabajo, el intercambio y la propiedad son los principios fundamentales de la cooperación humana en su vertiente social. La sociedad humana, por consiguiente, es una consecuencia histórica y praxeológica del desarrollo gradual de la división del trabajo. De ahí que obstaculizar el potencial espiritual de la cooperación social en el orden socioeconómico impide el proceso de civilización.

El surgimiento de la cooperación social no obedece a una causa final de la acción humana individual, sino a un proceso de secuencia de causas que dan lugar a principios rectores del orden social. Esto, por supuesto, da al traste con el carácter teleológico de las instituciones, estas no siempre han estado, distan de ser dadas, hechas, predeterminadas; por el contrario, son el fruto de las vicisitudes de las acciones humanas en el marco de las relaciones sociales. En este sentido, lo espontáneo de la cooperación social radica en que la razón humana tiene límites. De esto resulta que la interacción social no es una construcción deliberada del cálculo racional, de una ingeniería del cambio social a través del diseño artificial de las interacciones humanas alrededor del valor económico.

La cooperación social, por tanto, hace parte de la naturaleza de la acción humana, los individuos en acción tienden a apoyarse y colaborarse mutuamente como consecuencia inesperada. Como espíritu del intercambio y la división del trabajo, contiene la acción recíproca de la vida humana. La influencia de la acción recíproca no es unilateral, es compleja. Una acción no influye simplemente en otras acciones, estas, a su vez, se influyen en sí mismas e influyen en tal primera acción. Esto nos presenta el carácter complejo de la cooperación social, en la cual, por consiguiente, no es cierta la aplicación del axioma según el cual el todo es igual a sus partes. Esto en el sentido que el hombre social por medio de los beneficios de la cooperación puede hacer más cosas en un día que un individuo aislado en toda su vida.

La importancia particular de la cooperación social para la sociedad radica en la posibilidad de configuración económica e histórica de la realización del intercambio y la división del trabajo. Aquella eleva las cosas singulares y su significación para los hombres en la realidad objetiva, por encima de sus individualidades, no al mundo abstracto, sino al orden de los valores económicos que tienen como sustancia la vida de la acción recíproca. De nuevo, se argumenta por qué no es posible el mercado libre 
sin cooperación social, o sea, sin intercambio y división del trabajo. En definitiva, la cooperación social se propone como una institución espontánea que surge del ejercicio de las libertades individuales.

Es sugerente destacar un diálogo entre las principales distinciones y convergencias del anterior cuerpo conceptual: a) la cooperación social en Mises y Weber, surge de la relación de asociación; los individuos en el mercado libre logran fines con base en el intercambio voluntario b) el correspondiente principio rector de la cooperación social en cada autor, en su orden cronológico, podría ser: la propiedad, libertad monetaria, la asociación y la civilización; c) la razón moderada es instrumento para la cooperación social; d) el cálculo económico es un puente entre cooperación social y mercado libre, y e) la cooperación social es de carácter espontáneo.

\section{REFERENCIAS}

Eshelman, L. (1993). Ludwig von Mises on Principle. The Review of Austrian Economics, 6(2), 3-41.

Hayek, F.A.V. (1931/67). Prices and production. (2th ed.). New York: Augustus M. Kelly, Publishers New York.

Hayek, F.A.V. (1959/98). Los fundamentos de la libertad. (6a. ed.). Madrid, España: Unión Editorial.

Hayek, F.A.V. (1988/90). La fatal arrogancia. Los errores del socialismo. Madrid: Unión Editorial.

Hobbes, T. (1642/2000). De Cive. Elementos filosóficos sobre el ciudadano. Madrid: Alianza Editorial.

Hobbes, T. (1651/1928). Leviathan or the matter, forme and power of a commonwealth ecclesiasticall and civil. Oxford, London: Basil Blackwell.

Hobbes, T. (1651/2004). Leviatán o la materia, forma y poder de un Estado eclesiástico y civil. Madrid: Alianza Editorial.

Kirzner, I. (2001). Ludwig von Mises: The man and his economics. USA: ISI Books.

Mises, L.V. (1919/83). Nation, State and economy: Contributions to the politics and history of our time. California, USA: Institute for Humane Studies. Series in economic theory.

Mises, L.V. (1922/62). Socialism: An economic and sociological analysis. New Haven, USA: Yale University Press.

Mises, L V. (1927/2002). Liberalism: In the classical tradition. (3th ed.). Auburn: The Ludwig von Mises Institute.

Mises, L V. (1938/2000). The equations of mathematical economics and the problem of economic calculation in a socialist state. The Quarterly Journal of Austrian Economics, 3(1), 27-32.

Mises, L V. (1949/2007). La acción humana. Tratado de economía. (8th ed.). Madrid: Unión Editorial. 
Mises, L V. (1957/2003). Teoría e historia: una interpretación de la evolución social y económica. Madrid: Unión Editorial.

Roth, G. \& Schluchter, W. (1979). Max Weber's vision of history: Ethics and methods. Berkeley and Los Ángeles, California, USA: University of California Press.

Weber, K.E.M. (1905/2011). La ética protestante y el espíritu del capitalismo. (2a. ed.). Ciudad de México D. F., México: Fondo de Cultura Económica.

Weber, K.E.M. (1909/78). Economy and society. An outline of interpretative sociology (pp. xxxiiii-cx). Berkeley and Los Angeles, California, USA: University of California Press.

Weber, K.E.M. (1920/98). Ensayos sobre sociología de la religión. Tomo I. Madrid: Taurus.

Weber, K.E.M. (1922/73). Ensayos sobre metodología sociológica. Buenos Aires: Amorrortu Editores.

Weber, K.E.M.(1922/2014). Economía y sociedad. Esbozo de sociología comprensiva. (3a. ed.). México: Fondo de Cultura Económica.

Weber, K.E.M. (1923/2001). Historia económica general. (8a. Reimpresión). México: Fondo de Cultura Económica.

Zanotti, G.J. (2010). La filosofía política de Ludwig von Mises. Procesos de Mercado: Revista Europea de Economía Política, VII(2), 109-145. 